\title{
Correlation Between Revised Trauma Score Output and Head Trauma Mortality
}

\author{
Bagus Rahmat Santoso ${ }^{1}$, Eirene E.M. Gaghauna ${ }^{2}$ \\ \{ners_b4gs@yahoo.com ${ }^{1 *}$, eirenegaghauna@gmail.com ${ }^{2}$ \} \\ ${ }^{12}$ Emergency \& Critical Department, Nursing Program, Faculty of Health Sari Mulia University, \\ Banjarmasin, Indonesia \\ "nersb4gs@yahoo.com
}

\begin{abstract}
Head trauma is a problem of neurological disorder in the brain and has a high mortality rate. Head trauma incidence of America reached 500,000 cases, which are divided into $80 \%$ of mild head trauma, $10 \%$ of moderate trauma, and $10 \%$ of severe trauma. There for an accurate initial assessment method of prognosis of head trauma such as Revised Trauma Score is needed to predict the possibility of patient's mortality. Revised Trauma Score (RTS) is an assessment method that is accurate for predicting the level of brain damage. This study was Cohort design with accidental technique 46 people. The results of statistical test of Man-Whitney showed that there was a significant correlation between RTS scores output and head trauma mortality ( $\mathrm{p}<005)$. Quick and precise management are needed to decrease brain damage.
\end{abstract}

Keyword: Head injury, mortality, revised trauma score

\section{Introduction}

Head trauma is one of the leading causes of death and disability in the productive age group and mostly occurs due to traffic accidents. Head injury cases are most case who has risk for causing death and permanent disability in patients. World Health Organization (WHO) data on head injuries indicate $40-50 \%$ have permanent disability or disability. Therefore, someone who comes to the hospital with a head injury requires prompt and appropriate treatment so that patients avoid disability and death [1].

Head trauma is one of the leading causes of death and disability in the productive age group and mostly occurs due to traffic accidents. Head injury cases are the injury case who has most risk of causing death and permanent disability in patients. World Health Organization (WHO) data on head injuries indicate $40-50 \%$ have permanent disability or disability. Therefore, someone who comes to the hospital with a head injury requires prompt and appropriate treatment so that patients avoid disability and death [1].

The cause of death in head trauma patients according to the study of Awaloei, et.al (2016) due to the presence of cranial base fractures, diffuse brain injury, intracerebral hematoma and subdural hematoma. In the United States, the incidence of head trauma every year is estimated at 500,000 cases with a prevalence of $80 \%$ before death to hospital, $80 \%$ mild head trauma, $10 \%$ moderate head trauma and $10 \%$ severe head trauma, with a range of events from 15-44 years. The percentage of traffic accidents recorded as 48-58\% was obtained from head trauma from $20-28 \%$ falling to $3-9 \%$ due to acts of violence and sports activities [2]. 
Some of the suspected factors are the mechanism of injury, the initial Glasgow Coma Scale (GCS) score, hypotension, pupillary diameter and light reaction, computed tomography (CT) scan, alcohol use and drugs [3]). Monitoring Methods that can be used in predicting improvement or worsening in head injury patients are with RTS and GAP [4,5].

GCS is one component of the Revised Trauma Score (RTS) where GCS measurements indirectly indicate the level of functioning of the brain as a central function of control of all organs in the human body and quantitative gauges of severity of injuries that occur in patients with head trauma [6]. Head injury patients with GCS 15 then the mortality rate reaches $1 \%$, GCS 8-12 death rate reaches 5\% and GCS 8 the death rate rises to $40 \%$ [7]. So the lower the GCS assessment results and the more severe the level of neurological damage, the worse the prognosis of head injury patients [6].

According to the research results of Champion, et.al \& Irawan, et.al, (2010), RTS is easy to do and can estimate the prognosis more accurately if used for severe head trauma patients and patients with multitrauma where severe brain damage causes various damages. the control system of the body's defense including the respiratory and cardiovascular control system can even cause death.

\section{Methods}

The design of this study uses a cohort design in which the researcher observes or measures the variable using RTS when patient arrived immediately in Emergency Room, for the mortality variable measure when transfer from the emergency rooms [8]. The population in this research were all patients who suffered head injuries who were taken to the IGD Ulin Hospital Banjarmasin and the number of respondents sampled in this study amounted to 46 head trauma patients who entered the IGD Ulin Hospital in May-August 2018. How to take samples in This research uses accidental sampling technique based on coincidence, but in accordance with the requirements of respondents with head injuries in IGD Hospital Ulin Banjarmasin.

\section{Characteristic of Respondent classified based on numeric distribution}

\begin{tabular}{cccccc}
\hline & Mean & Median & Max & Min & St. Deviasi \\
\hline Age & 34.35 & 30.50 & 80 & 14 & 15.358 \\
\hline RTS & 6.91439 & 7.69550 & 7.841 & 2.628 & - \\
\hline
\end{tabular}

Characteristic of Respondent classified based on kategoric distribution

\begin{tabular}{lccc}
\hline & Man & Woman & Total \\
\hline Sex & 34 & 12 & 46 \\
\hline Mortality & Life & Death & \\
\hline
\end{tabular}

\section{Result}

From 46 respondents, the majority of respondents experienced head trauma with a mean value of 34.35 , a median of 30.50 with a maximum age of 80 years and a minimum of 14 years. Most of the respondents who experienced the head trauma were male, as many as 34 respondents $(73.9 \%)$. The average RTS value in patients was 6.91 with a maximum value of 
7,841 and a minimum of 2,628. Of the total respondents in the study sample 9 patients experienced death.

\section{Discussion}

The 46 respondents who experienced head trauma with a mean value of 6.91439 , a median of 7.69550, a maximum of 7,841, a minimum of 2,628. Can be interpreted the value of RTS with heavy categories have an important role in death. Based on the number of 46 respondents who died with a high risk RTS death rate amounted to 7 respondents with a range of RTS 2 to $\leq 6$ which the lower the RTS value the higher the mortality rate.

RTS is the easiest score to use in the prehospital phase and field triage that can be done by doctors or paramedics. In line with the results of this study, RTS has become a standard assessment in the ATLS protocol. Physiological parameters (respiratory rate, systolic blood pressure, and GCS) can change at any time according to the severity of the injury and treatment provided, so that aside from being a scoring instrument in the prehospital or triage phase, RTS can also be used as an assessment as long as the patient is still in treatment but with periodic checks, not just in one point of time [9].

\begin{tabular}{cccc}
\multicolumn{3}{c}{$\begin{array}{c}\text { Bivariat Analyzes between RTS and Mortalitiy Rate } \\
\text { of patient with head trauma case }\end{array}$} \\
\hline \multicolumn{4}{c}{ Revised Trauma Score vs Mortality } \\
\hline & Life & Death \\
\hline Mean & Median & Mean & Median \\
\hline 7.39476 & 7.84100 & 80,344 & 4.09400 \\
\hline Max & Min & Max & Min \\
\hline 7.841 & 5.676 & 7.841 & 2.628 \\
\hline \multicolumn{4}{c}{ Mann-Whitney Test (p) value $=\mathbf{0 , 0 0 0}$} \\
\hline
\end{tabular}

Based on the results of the normality test the $\mathrm{P}<0.05$ value was obtained which means the distribution was abnormal and using the Mann-Whitney alternative test obtained $\mathrm{p}$ value = $0.000>0.05$ which means there was a relationship between RTS and mortality of head trauma patients. RTS can also be used as an assessment as long as the patient is still in treatment but with periodic examinations, not just in one point of time RTS is the easiest score to use in the prehospital phase and field triage that can be done by doctors or paramedics in assessing the mortality of trauma patients [9].

In line with the results of this study, RTS has become a standard assessment in the ATLS protocol. Physiological parameters (respiratory frequency, systolic blood pressure, and GCS) can change at any time according to the severity of the injury and treatment provided, so that other than as a scoring instrument in the prehospital and triage phase.

RTS assessment can identify more than $97 \%$ of people who will die if they are not treated. The ability of RTS in determining conditions that can cause 76.9\% [10]. However, in view research in the Netherlands, RTS has a lower predictive value compared to the results of previous RTS research [11]. 


\section{Conclusion}

The RTS results from 46 respondents who experienced head trauma with the most dominant frequency causing patients to die were in the mean category 80,344, median 4,09400 , maximum 7,841, minimum 2,628 , so it could be interpreted that head injury patients with a moderate category would potentially experience death.

\section{Acknowledgments}

Many factors can play a role in causing death in head trauma patients. Researchers only see from one side that plays a role in causing death.

\section{Reference:}

[1] Qureshi, J. S., et al. Head Injury Triage in a Sub Saharan African Urban Population. International Journal of Surgery. pp. 265-269. (2013).

[2] Awaloei, A.C., Mallo, N.T.S., \& Tomuka, D. Gambaran Cedera Kepala Yang Menyebabkan Kematian di Bagian Forensik dan Medikolegal RSUP Prof. Dr. R. D. Kandou Periode Juni 2015 - Juli 2016. Jurnal e-Clinic. pp. 1-5. (2016).

[3] Li, J. \& Jiang, J. Chinese Head Trauma Data Bank: Effect of Hyperthermia on the Outcome of Acute Head Trauma Patients. Journal of Neurotrauma. pp. 96-100. (2012).

[4] Tirtayasa, P.M.W. \& Philippi, B. Prediction of Mortality Rate of Trauma Patients in Emergency Room at Cipto Mangunkusumo Hospital by Several Scoring Systems. Med J Indones. pp. 227-231. (2013).

[5] Kondo, Y., Abe, T., Kohshi, K., Tokuda, Y., Cook, E.F. and Kukita, I. Revised Trauma Scoring System to Predict In Hospital Mortality in the Emergency Department: Glasgow Coma Scale, Age, and Systolic Blood Pressure Score. Critical Care. pp. 1-8. (2011).

[6] Ting, H.W., Chen, M.S., Hsich, Y.C., \& Chan, C.L. Good Mortality Prediction by Glasgow Coma Scale for Neurosurgical Patients. J Chin Med Assoc. pp. 139-143. (2010).

[7] Grace, P.A., \& Borley, N.R. At a Glance Ilmu Bedah (3. ed). Erlangga, Jakarta (2007).

[8] Sastroasmoro, S., \& Ismael, S. Dasar-Dasar Metodologi Penelitian Klinis (4 ed.). Sagung Seto, Jakarta. (2011).

[9] Ranti, J.S.: Aplikasi Revised Trauma Score, Injury Severity Score, dan Trauma and Injury Severity Score Dalam Memprediksi Mortalitas Pada Pasien Multitrauma di IRDB BLU RSUP Prof. Dr. R. D. Kandou Manado. Jurnal Biomedik. Pp. 30-35. (2016).

[10] Oyetunji, T., Crompton, J.G., Efron, D.T., Haut, E.R., et.al. Simplifying Physiologic Injury Severity Measurement for Predicting Trauma Outcomes. Journal of Surgical Research. pp. 627-632. (2010).

[11] Irawan, H., Setiawan, F., Dewi, Dewanto G. Perbandingan Glasgow Coma Scale dan Revised Trauma Score Dalam Memprediksi Disabilitas Pasien Trauma Kepala di RS. Atma Jaya. Majalah Kedokteran Indonesia. Vol. 60. No. 10. (2010). 